\title{
How Predictable is Local Erosion Rate in Eroding Landscapes?
}

\author{
Leslie E. Hasbargen and Chris Paola \\ Department of Geology and Geophysics, and St. Anthony Falls Laboratory, \\ University of Minnesota, Minneapolis, Minnesota
}

The current suite of numerical landscape models suggest that, under steady forcing, erosional landscapes evolve to a static steady state in which erosion everywhere balances uplift. Among other things, this implies that the only limitation on our ability to predict the future configuration of a landscape is imperfect knowledge of initial conditions and stochastic forcing events (e.g. storms, earthquakes). These are formidable obstacles to prediction, but they are apparently not the only ones. We have constructed a physical model of a drainage basin which erodes through several units of relief. We conducted several constantly forced runs at various base level fall and rainfall rates. The landscapes develop $3^{\text {rd }}$ to $5^{\text {th }}$ order stream networks, and erode by surface runoff, hillslope failures, and upstream migrating knickpoints. Within the constraints of an overall balance between uplift and erosion, interactions between streams and hillslopes result in spatially and temporally variable erosion rates. These results suggest that eroding drainage basins at steady forcing are intrinsically dynamic structures. Current numerical models do not exhibit the same level of erosional variability at steady forcing, suggesting that some feedback mechanisms may be missing from model formulations. The presence of inherent dynamism in eroding landscapes could seriously complicate predictions of local erosion rate, even if an average balance between uplift and erosion rate has been attained for a given drainage basin.

\section{INTRODUCTION}

The legacy of chaos theory is the recognition that there are systems that we may not be able to predict even with perfect knowledge of their governing equations. We approach prediction in a chaotic system differently than in a classical deterministic system. For a chaotic system, at least part of our effort must be aimed at predicting statistical properties of the system rather than exact sequences of events. Predicting statistical properties of a geomorphic system (e.g. mean and variance) is no less "rigorous" than predicting classical deterministic properties (e.g. wavelength), though it may require considerably more computational effort.

Prediction in Geomorphology

Geophysical Monograph 135

Copyright 2003 by the American Geophysical Union 10.1029/135GM16
Before proceeding further, it is worth defining some terms. We follow convention and use stochastic to describe dynamics that for all practical purposes cannot be predicted exactly, i.e. that must be described probabilistically. Random behavior is a type of stochastic behavior in which the probability structure is very simple, e.g. white noise. Stochastic behavior in a system may be the result of stochastic forcing, in which case we refer to it as externally forced, or it may arise spontaneously as a result of the system's internal dynamics, in which case we refer to it as intrinsic. The idea that a geomorphic system may show strongly unpredictable behavior with no external cause is well known in sedimentary geology, where it is associated with processes like avulsion and is known as autocyclicity. The use of 'cycle' in this context has historical roots and does not imply a welldefined repeat period. Steady state refers to a system that is balancing inputs (i.e., uplift) to and outputs (i.e., erosion) from the system. Static steady state implies uniform flux divergence at any scale (time or space), and no deviation 
from the average divergence exists. A static steady state system may or may not be forced at the boundaries of the system. Dynamic steady state implies non-zero forcing at the boundaries of the system, and global fluxes into and out of the system balance. The local fluxes, however, may exhibit deviations from the global average.

Erosional landscapes have been described in stochastic terms at least since the pioneering work of Shreve on random drainage networks [Shreve, 1975; Shreve, 1967]. Numerical landscape models [Whipple and Tucker, 1999; Moglen and Bras, 1995; Howard, 1994; Beaumont et al., 1992; and Willgoose et al., 1991] generate geometrically reasonable networks, and capture one important part of landscape unpredictability: sensitivity to initial conditions. One could not generally predict the final form of the landscape from a given initial topography, and slight changes in initial topography can produce quite different-looking landscapes. Nonetheless, as far as we are aware, stochastic dynamics in current landscape models are limited to the relation between initial conditions and final network configuration. None of these models produces ongoing, intrinsically generated stochastic dynamics. Forced with steady uplift and rainfall, and constant substrate conditions, these models evolve to a steady state that, while dependent in its details on the exact starting topography, is everywhere adjusted so that erosion rate locally balances uplift rate (static steady state). In this condition, the topography cannot continue to evolve.

It is difficult to know to what extent this is a good description of the behavior of natural landscapes. Landscape modelers are as aware as anyone else of dramatic, discrete erosional events (e.g. landslides, knickpoints) that suggest that erosion is discontinuous on short time scales. What is not known is the extent to which these events are just minor 'noise' about a condition that would be effectively static (given steady forcing) on the length and time scales for which the models are intended, or whether they portend a more fundamental instability that would prevent an eroding landscape from ever reaching the static condition that current models predict.

In order to address dynamics that might exist beyond event scale fluctuations, longer term measurements of landscape form are required, preferably over some time or length scale in which an average erosion rate is well-characterized. A simple and natural choice for this length scale might be drainage basin relief. The difficulty of investigating erosion dynamics at this scale is that the time required to erode through a significant portion of relief is quite long. For instance, a landscape eroding at $1 \mathrm{~mm} / \mathrm{yr}$ with maximum relief of $1 \mathrm{~km}$ requires $100 \mathrm{kyr}$ to erode through $1 / 10$ of the relief. If we could observe erosion across the landscape on this time scale, what would it look like? Is the entire surface eroding at a uniform rate? If not, what kinds of behavior are possible? Are erosion events distributed randomly in space and time? Or is erosion organized locally in some way?

Physically-based numerical models of eroding drainage basins offer a means of studying erosional behavior over longer time scales [Whipple and Tucker, 1999; Moglen and Bras, 1995; Howard, 1994; Beaumont et al., 1992; Willgoose et al., 1991]. A commonly employed erosion law is the shear stress or stream power law:

$$
\partial z / \partial t=U-\left(b A^{m} S^{n}+c S\right)
$$

where $z$ is elevation, $t$ is time, $U$ is tectonic uplift rate, $A$ is cumulative upstream area draining to an element, $S$ is the local slope in the steepest downstream direction, $b$ and $c$ are constant coefficients related to the erosive potential of the process, and $m$ and $n$ are calibrated scaling parameters that incorporate erosivity (downstream width-depth-velocity scaling relations, shear stress and entrainment relations, and average climatic conditions) and erodibility (rock properties). Three dimensional landscape models are usually allowed to evolve from an initial random topography. Some evolution of the network occurs after a global balance of uplift and erosion has been attained. Howard [1994] notes that after eroding through 3 relief distances, the landscapes are stationary, and erode everywhere at the same rate (static steady state).

Interestingly, this erosion law has kinematic wave solutions to perturbations. An abrupt change in uplift rate, for instance, would propagate as a wave across the landscape [Whipple and Tucker, 1999]. While theory for erosional wave propagation across a numerical landscape exists, we point out that the mechanism of wave propagation is an external change in forcing. No existing model for drainage basin erosion spontaneously generates knickpoints in the absence of changes in forcing conditions. At steady forcing, stability of the landscape is inevitable in current numerical models.

Reported erosion rates in natural drainage basins show substantial spatial variability. Average hillslope erosion rates in the Oregon coast ranges vary $\sim 50 \%$, with a range three to four times the minimum erosion rate [Reneau and Dietrich, 1991]. Erosion rates vary by a factor of 10 over a small drainage basin in northeastern California, USA [Granger et al., 1996]. Deep-seated landsliding accounts for a large fraction of hillslope erosion in the Southern Alps of New Zealand for short time scales (tens of years) [Hovius et al., 1997], and in Taiwan [Hovius et al., 2000]. Power law distributions for shallow landslides have been reported for Queen Charlotte Islands, Canada [Martin et al., 2002, in press]. A power law relation between landslide magnitude and frequency implies large spatial and temporal variations in erosion rate. Erosion rates derived from cosmogenic 
nuclides for small catchments in the Sierra Nevada of California exhibit order of magnitude ranges [Riebe et al., 2000]. Spatial erosion rates during the Holocene for several small $\left(<100 \mathrm{~km}^{2}\right)$ drainage basins in Nevada, USA exhibit comparable variability [Miller et al., 2001]. These field studies all point to substantial variability in erosion rates. Is this due to external effects, such as variability in climate, tectonics, or lithology, or could it be due to intrinsic interactions between hillslopes and streams?

Long-term system behavior in natural eroding landscapes remains somewhat hypothetical. Significant progress has been made toward obtaining surface exposure ages and erosion rates on a land surface using cosmogenic nuclide concentrations [Heimsath et al., 1999; Granger et al., 1996; Brown et al., 1995; Bierman, 1992; Lal, 1991] , and low temperature geochronometry is yielding exhumation rates [e.g., Armstrong et al., 2000; Brandon et al., 1998], but we know of no study that has detailed surface ages and erosion rates in an eroding drainage basin at a resolution required to make statements concerning long term patterns of erosion. Natural landscapes are also subject to significant fluctuations in climatic, tectonic, and base level conditions that further complicate study of dynamic systematic behavior in an eroding drainage basin.

An alternative means of investigating landscape evolution has been the use of small-scale erosion facilities [Lague et al., 2002; Davy et al., 2000; Hasbargen and Paola, 2000; Hancock, 1997; Czirok et al., 1993; Parker, 1977]. Small scale physical experiments allow manipulation of boundary conditions, and hence allow for a range of conditions to be explored, such as changes in landscape form due to rainfall rate [Hancock, 1997; Parker, 1977], or the effect of initial surface slope on network development [Phillips and Schumm, 1987]. Further, measurements of landscape form and mass fluxes across system boundaries can be used to test numerical model predictions. There are limitations to physical experiments, in that some forces become important in the total force balance at small scales, such as water surface tension and molecular viscosity, that are not representative of anything at a larger scale, and may not be well-represented in a numerical model either. Physical experiments offer, however, a view into the dynamics of drainage basins eroded by surface runoff and slope failures, and thus may offer insight into longer term evolution of larger drainage basins that erode with similar processes.

We designed an experiment to investigate the systematic erosional behavior of a drainage basin at steady forcing. Our experiment is a simplified model of an eroding drainage basin experiencing constant, uniform rainfall and uplift rates, and a homogeneous substrate. We have eliminated vegetation and chemical weathering, and minimized sub- strate, rainfall, and uplift variability in an effort to isolate basic physical processes of surface runoff, incision, and mass transport within the framework of a dendritic (i.e., convergent flow) drainage basin. The goal of these experiments is to test the idea that drainage basins erode at spatially uniform rates under constant forcing conditions, and ultimately to understand the kinds of behavior that are possible within an eroding drainage basin.

\section{EXPERIMENTAL DESIGN AND RUN CONDITIONS}

Our experimental drainage basin is an elliptical tank, with a surface area of $6477 \mathrm{~cm}^{2}$ (99 $\mathrm{cm}$ long and $87 \mathrm{~cm}$ wide), and depth of $100 \mathrm{~cm}$. A motor-controlled sliding gate $(1 \mathrm{~cm}$ wide) functions as the outlet to the basin (Figure 1). A radial mist apparatus located $1.5 \mathrm{~m}$ above the tank generates rainfall. Oscillating $23 \mathrm{~cm}$ fans situated $2 \mathrm{~m}$ above the tank are used to break up stable air circulation patterns and promote mixing of rainfall in the facility. The tank was constructed from sheet metal, and rests on a plywood base supported by concrete blocks. An electric variable speed motor allows us to drop the outlet at rates from 0.5 to $50 \mu \mathrm{m} / \mathrm{s}$. During the course of each run, outlet elevation above datum was measured on a fixed $\mathrm{mm}$ scale tape. Base level curves were constructed from these measurements, and base level fall rates were derived from the regression coefficient of elevation against time. We note that this configuration (a dropping base level) is equivalent to spatially uniform uplift across the basin (block uplift).
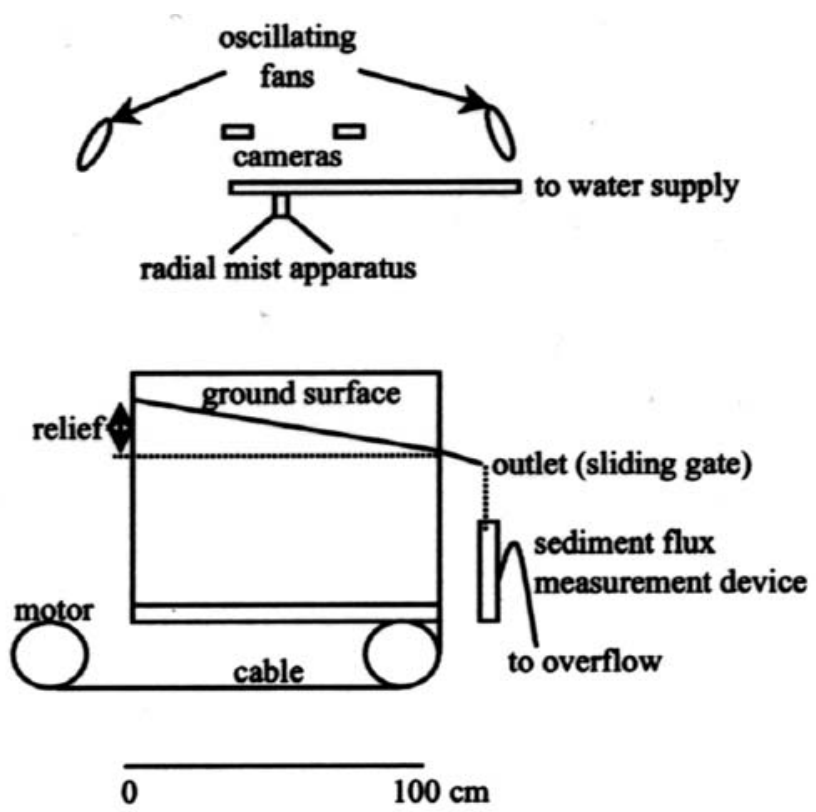

Figure 1. Schematic cross section of erosion facility. 
The substrate consists of kaolinite and silica flour $\left(d_{50}=\right.$ $45 \mu \mathrm{m})$ mixed in a cement mixer (1:100 clay/silt), with water added until the mix is capable of flowing. We then poured the mix into the basin, and allowed it to settle overnight. Settling produces a standing body of water, which upon draining reveals a flat surface pocked with small mud volcanoes ( $<2 \mathrm{~cm}$ in diameter).

Rainfall spatial patterns were measured by collecting rain in pans scattered over the basin prior to each run. The coefficient of variation of rainfall for short time intervals (5-10 minutes) is $\sim 15 \%$, and decreases to $\sim 5 \%$ for measurement intervals longer than 30 minutes. Total water discharge (runoff) was measured at the outlet during each run, and provides an additional measure of temporal rainfall variation. This measure includes runoff from rainfall as well as groundwater contained in the substrate. The coefficient of variation for total runoff ranges from $1.8 \%$ for Run 6 to $12.5 \%$ for Run 3 .

We have conducted five runs at various uplift and rainfall rates (held constant during each run) that eroded through several relief units (see Table 1 for run conditions). We define a relief unit $\left(H_{r}\right)$ as the maximum relief at complete dissection of the initial flat surface. After complete dissection, the run continues until the outlet has reached the bottom of the tank. One run (Run 1) was turned off overnight, and the surface dried out. The response time to balance uplift and erosion during rehydration for Run 1 was $\sim 1 \mathrm{hr}$, or $\sim 0.04$ $H_{r}$ of erosion. Run 1 eroded through $\sim 1.5 H_{r}$. We noted that the landscape was still evolving at the end of the run, so we added $20 \mathrm{~cm}$ to the tank walls for subsequent runs to allow the landscape to erode for a longer time at dynamic steady state conditions. The remaining runs were conducted continuously, with minor interruptions in base level fall and rainfall for photographs.

Table 1. Experimental Run Conditions

\begin{tabular}{ccccccccc}
\hline $\begin{array}{r}\text { run \# of } \\
\text { id data } \\
\text { sets }\end{array}$ & $\begin{array}{c}\text { uplift } \\
\text { rate }\end{array}$ & $\begin{array}{c}\text { rainfall } \\
\text { rate }) \\
(\mu \mathrm{m} / \mathrm{s})\end{array}$ & $\begin{array}{c}\text { water/ } \\
\text { rock } \\
(r / \mathrm{m})^{\mathrm{a}}\end{array}$ & $\begin{array}{c}\text { basin } \\
\text { depth } \\
(\mathrm{cm})\end{array}$ & $\begin{array}{c}\text { grain } \\
\text { size } \\
\left(\mathrm{d}_{50}\right) \\
(\mu \mathrm{m})\end{array}$ & $\begin{array}{c}\text { clay: } \\
\text { silt }\end{array}$ & $\begin{array}{c}\text { wenstrate } \\
\left(\mathrm{g} / \mathrm{cm}^{3}\right)\end{array}$ \\
\hline 1 & 10 & 2.16 & 3.8 & 1.0 & 43.8 & 40 & 1 & 1.7 \\
2 & 10 & 2.82 & 3.86 & 0.8 & 84.8 & 40 & 1 & 1.7 \\
3 & 3 & 6.02 & 6.1 & 0.6 & 82.9 & 40 & 1 & 1.7 \\
4 & 11 & 0.55 & 6.2 & 6.4 & 88.1 & 40 & 1 & 1.7 \\
6 & 32 & 0.94 & 13.5 & 8.2 & 88.8 & 40 & 1 & 1.7 \\
\hline
\end{tabular}

${ }^{\mathrm{a}}$ Mass forcing rate (velocity $*$ density) ratio: $\left(r \rho_{W}\right) /\left(u \rho_{S}\right)$, where $\rho_{W}$ is rain density, and is $\rho_{s}$ substrate density.

b Analyses generously provided by John Pitlick, U. of Colorado, Boulder. Analyses performed with a Malvern long bed laser particle size analyzer.
We organize our runs according to the ratio of rainfall/uplift mass rates $(r / u)$, i.e., rainfall rate $(\mathrm{L} / \mathrm{T})$ divided by uplift rate $(\mathrm{L} / \mathrm{T})$ multiplied by their respective densities. In essence, $r / u$ is the average vertical mass flux of rainfall over a unit area, divided by the vertical mass flux of substrate per unit area due to uplift. This nondimensional number can be thought of as a water to rock ratio, or qualitatively as a measure of forcing conditions that range from dry uplift to wet uplift, or more simply as dilute (high $r / u$ ) or concentrated (low $r / u$ ) erosion conditions. For runs presented in this paper, $r / u$ varies from 0.6 to 8.2. We hypothesize that for a given substrate at steady forcing, the topographic form is set by surface shear stress (runoff) and substrate resistance to gravitational forces (hillslope failures). At high $r / u$, surface runoff is sufficient to remove all of the material supplied by uplift. A higher drainage density results, and hillslope failures decrease in size. At low $r / u$, slopes develop that enhance hillslope failures, resulting in a larger range of hillslope failure size.

\section{MEASUREMENT METHODOLOGY}

Our data collection was initially guided by the concept that a landscape develops a static form at constant forcing conditions. In order to test this idea, we developed methods to measure topography and monitor planform changes, as well as collect detailed records of sediment and water leaving the erosion facility.

In order to address overall planform stability of drainage basin features, we used a VHS video camcorder modified for time-lapse image collection. An automated shutoff valve was inserted into the rainfall water line for runs 3,4 , and 6 , to allow for clearer images for time-lapse video. Shutoff times varied for the runs, in the range of 5-10 s in duration every 250 to $500 \mathrm{~s}$. Time lapse video capture rates varied from $2 \mathrm{~s}$ of video (30 frames/s) every $250 \mathrm{~s}$ to $1 \mathrm{~s}$ every $500 \mathrm{~s}$. We later subsampled the videotape, and transferred the record to digital format for viewing on a computer. Time-lapse records allow us to compress time, and reveal process interactions at longer time scales not readily accessible at real time conditions, such as interactions between hillslope failures and knickpoint propagation. Longer term divide migration is also more readily detectable.

For detailed measurements of landscape form, we used stereo digital photographs to develop gridded elevation models of the landform. The process involves several steps. Photographic coordinates of measured benchmarks on the basin were used to orient the images in the ground reference frame. Correlated features (pixels) were automatically extracted from stereo pairs. Given known image orientations, elevations can be derived from solutions to collinearity 


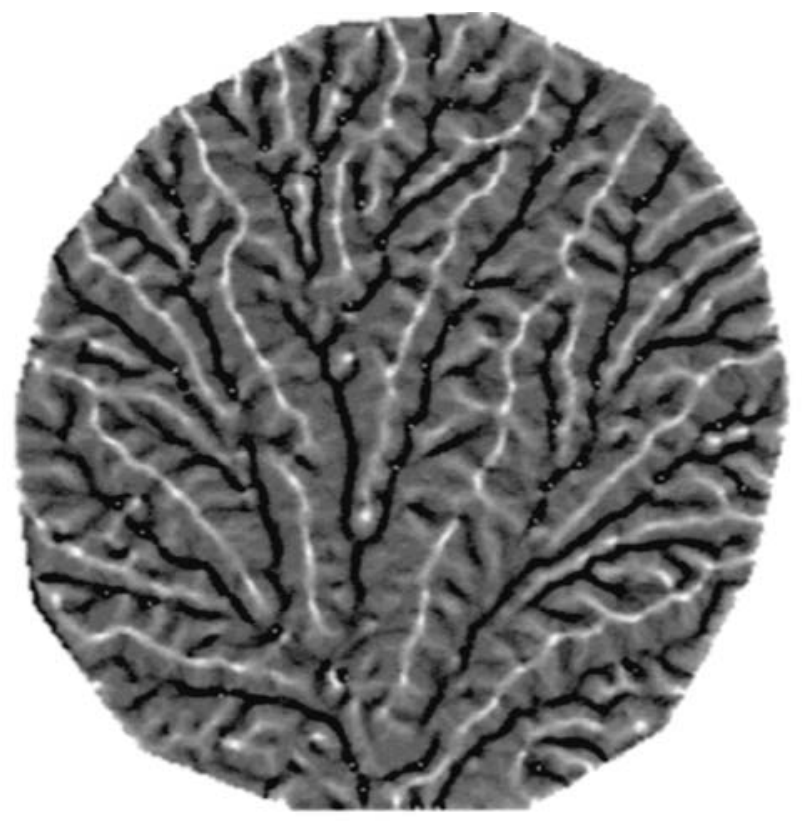

Figure 2. Local relative height map for Run 4 (runoff-dominated erosion, $r / u=6.4$ ). Width of image is $87 \mathrm{~cm}$, maximum relief is $16.7 \mathrm{~cm}$, grid spacing is $4 \mathrm{~mm}$. Local relative height is the number of cells in a gliding box $(5 \times 5$ pixels) lower than the center cell in the box, divided by the total number of cells in the box. Relative height values range from 0 (local depressions) to 1 (local peaks).

equations for correlated points [Wolf, 1983]. The precision of photogrammetric solutions using a 1280 x 960 pixel resolution camera is modest. Elevation changes calculated for single pixel shifts range from 7 to $20 \mathrm{~mm}$, depending on the distance between the ground surface and camera, and the field of view. However, a fair amount of detail can be discriminated from the elevation fields derived from this method (Figure 2).

Typically, 30,000 to 40,000 correlated points are collected from each stereo pair of photographs. After computing ground coordinates from correlated photographic points, the ground coordinates are read into a grid at $7 \mathrm{~mm}$ spacing (there are 12,757 grid points in a $7 \mathrm{~mm}$ grid with boundaries coincident with the erosion facility walls). We then filter the grid for extreme slopes $(>250 \%)$, and average the grid with three passes of a moving window ( $3 \times 3$ pixels). We performed this set of operations on all of the grids. Filtering extreme slopes removes faulty correlations introduced by automated image correlation. Smoothing removes stepped increments in elevation due to the resolution of the digital images (1280x960 pixels).

\section{OBSERVATIONS AND MEASUREMENTS}

At the beginning of each run, streams incise headward from the outlet into the initial flat surface. Measurements of

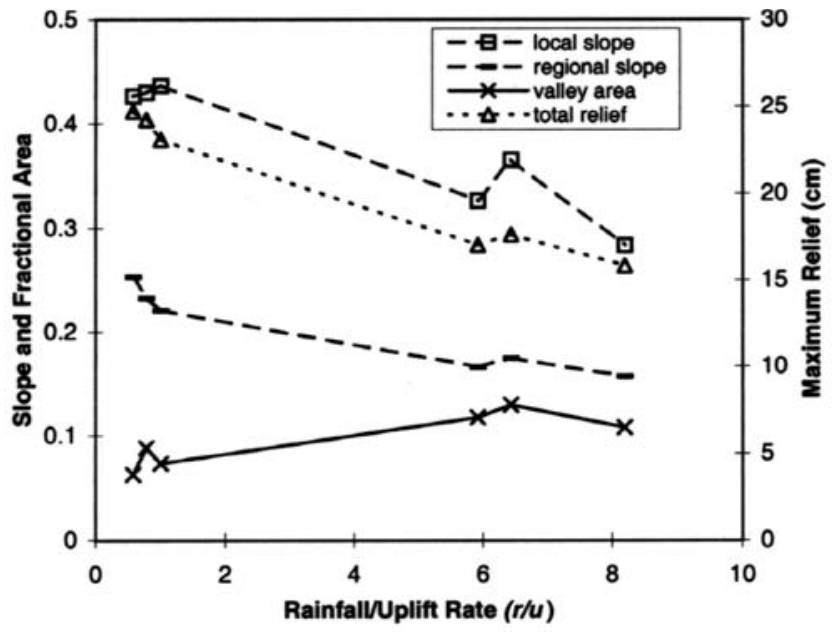

Figure 3. Average topographic measures plotted against forcing conditions. Local slope is the average steepest descent slope. Regional slope is the average regression coefficient derived from plots elevation against distance from the outlet. Total relief is the average maximum range in elevation. Valley area is the fractional area of the basin occupied by cells with local relative height values $<0.375$ in a moving $5 \times 5$ pixel window (recall local relative height ranks a cell from 0 (depression) to 1 (peak)). Ranges in measured values vary $\sim 10 \%$ (See Table 3 ). Note slope and relief closely track each other. Valley area increases slightly with $r / u$, suggesting stream networks advance into smaller areas at higher $r / u$ conditions.

sediment flux at the outlet indicate that erosion balances uplift roughly at the time of complete dissection of the initial surface. Sediment flux varies modestly after complete dissection, with a coefficient of variation ranging from $\sim 15 \%$ for run 3 to $\sim 7 \%$ for run 1 . The dominant erosive process is surface runoff that self-organizes into a dendritic stream network. The landscape is forced with continuous uplift and hence is predominantly erosional. However, we note there are always some valleys with temporary sediment storage. This is true for all of the runs we have conducted. Knickpoint (an oversteepened section in a stream) generation and migration are common in all of the runs. Knickpoints propagate upstream through the network, and have the appearance of waves, wrapping around and lapping against ridges, and re-excavating valleys with stored sediment. Knickpoint propagation experiences significant interference from hillslope failures in lower $r / u$ runs, and incised stream reaches are frequently overwhelmed with sediment, temporarily halting the advance of the knickpoint. While surface runoff performs the bulk of the work in eroding and transporting sediment out of the system, knickpoints clearly assist in excavation of stored sediment and incision into the substrate.

We also observe areas of very low relief, strongly resembling terraces, bounded by incising streams. The areas tend 
Table 2. Relief and Slope Statistics After Complete Dissection.

\begin{tabular}{lccccc}
\hline & run 3 & run 2 & run 1 & run 4 & run 6 \\
water/ rock $(r / u)$ & 0.6 & 0.8 & 1.0 & 6.4 & 8.2 \\
\hline maximum relief $(\mathrm{cm})$ & 25.2 & 24.2 & 23.1 & 17.6 & 15.8 \\
local slope & 0.43 & 0.43 & 0.44 & 0.37 & 0.28 \\
regional slope & 0.26 & 0.23 & 0.22 & 0.17 & 0.16 \\
area-slope exponent & -0.13 & -0.14 & -0.16 & -0.15 & -0.13 \\
area-slope intercept & 0.46 & 0.45 & 0.48 & 0.34 & 0.26 \\
\hline
\end{tabular}

to be rather small, on the order of $10-50 \mathrm{~cm}^{2}$, and somewhat lenticular in plan view. Over time these areas can grow into well-defined ridges, though frequently they are annihilated by migrating stream channels.

As noted above, we used time series of stereophotographs to derive elevation data sets for each run. The number of data sets varies between runs from 3 for Run 3 to 32 for Run 6 (see Table 1). We computed the distribution of elevation and slope, average and standard deviation of elevation as a function of distance from the outlet, and the exponent and intercept for the slope-area relation for each data set. Average values of maximum relief, local slope, and regional slope are plotted graphically against $r / u$ in Figure 3, and demonstrate that these measures vary systematically with forcing conditions. Time-averaged values for area-slope parameters are given in Table 2. Coefficients of variation (derived from the range in average values in all data sets after complete dissection) for these values are listed in Table 3. Note that we did not compute variances for area-slope parameters. Average values of relief and slope vary less than $10 \%$ for each run at steady state conditions, indicating that a stable statistical form develops in our experimental landscapes.
Table 3. Coefficient of Variation $(\sigma / \mu)$ For Relief and Slope.

\begin{tabular}{lccccc}
\hline & run 3 & run 2 & run 1 & run 4 & run 6 \\
water/ rock $(r / u)$ & 0.6 & 0.8 & 1.0 & 6.4 & 8.2 \\
\hline maximum relief & 0.047 & 0.073 & 0.064 & 0.087 & 0.083 \\
local slope & 0.072 & 0.064 & 0.110 & 0.134 & 0.088 \\
regional slope & 0.063 & 0.078 & 0.055 & 0.060 & 0.107 \\
\hline
\end{tabular}

TEMPORAL MEASURES OF DYNAMISM

We now show that within a statistically stable form at steady forcing, temporal and spatial erosion rates vary substantially. We calculate local erosion rates by differencing gridded elevation data sets on a cell by cell basis, and dividing by the time separation between the data sets. The result is a spatial pattern of erosion rate between the two data sets (Figure 4). We performed this operation for all possible grid pairs for Runs 1,2,4, and 6 .

To assess the spatial variance of erosion rate, we calculate the mean $(\mu)$ and standard deviation $(\sigma)$ of erosion rate for each pair of grids. We then plot the coefficient of variation $(\sigma / \mu)$ against the time separation between the grids. We perform this set of operations for all possible pairs of grids for each run. We did not perform this calculation for run 3, due to the limited number (three) of gridded data sets. If the landform were eroding at a spatially uniform rate, the coefficient of variation would be zero. If the time separation between grids is very long, such that the average vertical distance between grids is large relative to the local relief, the coefficient of variation again approaches a value of zero. Short and intermediate time scales for steadily forced landforms offer a means of discriminating between spatially uniform or spatially nonuniform erosion.
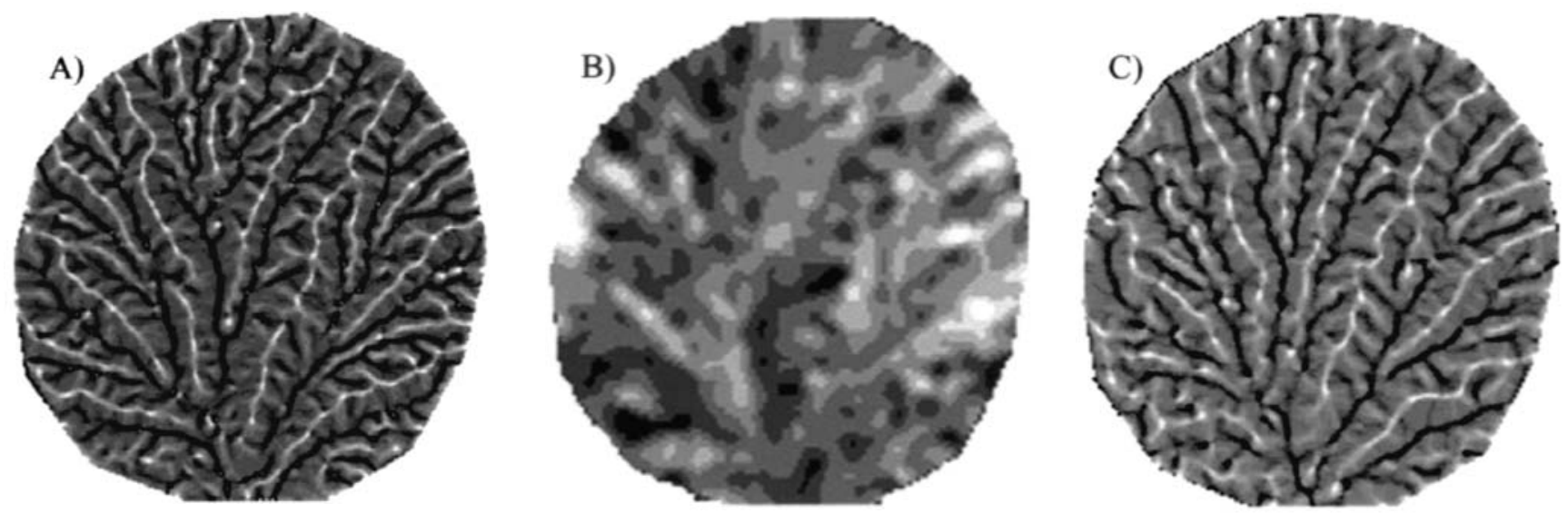

Figure 4. Spatial erosion rates for two grids separated vertically by $7 \mathrm{~cm}$ for Run $4(r / u=6.2)$. A) Local relative height for the first grid of the differenced pair. B) Gray scaled plot of spatial erosion rates. White represents a high erosion rate $(0.81 \mu \mathrm{m} / \mathrm{s})$, black is low $(0.42 \mu \mathrm{m} / \mathrm{s})$, with an average erosion rate of $0.62 \mu \mathrm{m} / \mathrm{s}$. C) Local relative height for the second grid of the pair. Maximum elevation range for each grid is $17.5 \mathrm{~cm}$ (a) and $15.4 \mathrm{~cm}$ (c). Width of each image is $87 \mathrm{~cm}$. Spatial resolution is $7 \mathrm{~mm} /$ pixel. 


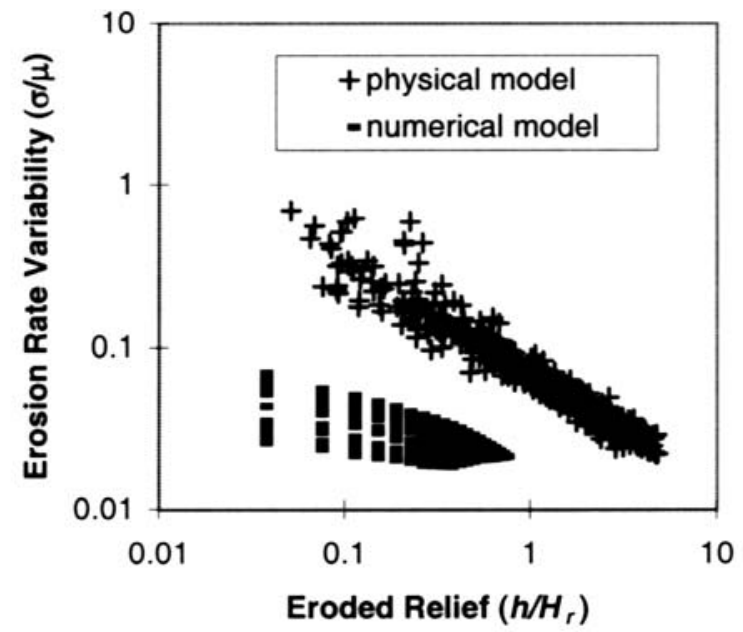

Figure 5. Coefficient of variation of steady state erosion rate $(\sigma / \mu)$ plotted against eroded relief for runs after complete dissection. Note the axes are logarithmic. Power law exponents for individual runs vary over a narrow range from -0.66 to -0.74 . Spatial erosion rates from a numerical erosion model demonstrate roughly order of magnitude lower variability in erosion. Note, data was extracted from numerical model after erosion balanced uplift, but before model reached a static steady state.

In order to eliminate scale dependence of time in our experiment (we measured time in seconds), we multiplied time by uplift rate, which yields a distance $h$, and divided $h$ by the relief at dissection $\left(H_{r}\right)$. This yields a nondimensional temporal measure in units of fractional relief. We plot the coefficient of variation of erosion rate against fractional relief for runs 1,2,4, and 6 (Figure 5). A power law relationship exists between the variance of erosion rate and vertical eroded distance, with a characteristic exponent about $-2 / 3$. Data from different runs plot on the same trend, implying that erosional variability is not sensitive to forcing conditions in our experiments. We attribute erosional variability to knickpoint migration, hillslope failures, and ridge migration. For comparison, we plot the typical erosion rate variability of an evolving stream power based gridded numerical model (simplified after Howard, 1994) after a balance between uplift and erosion rate has been attained. Numerical erosional variability is roughly an order of magnitude lower than for experimental landforms. Note that ultimately the variability goes to nil for all numerical models at steady forcing.

Changes in local flow direction offer another measure of landscape stability. We first calculate the flow direction vector in the steepest descent direction on a cell by cell basis for a gridded data set. We then compute the change in flow direction on a cell by cell basis by taking the dot product of the flow direction vectors between two grids. The dot product (that is, $\cos (\alpha)$, where $\alpha$ is the angle between vectors) returns

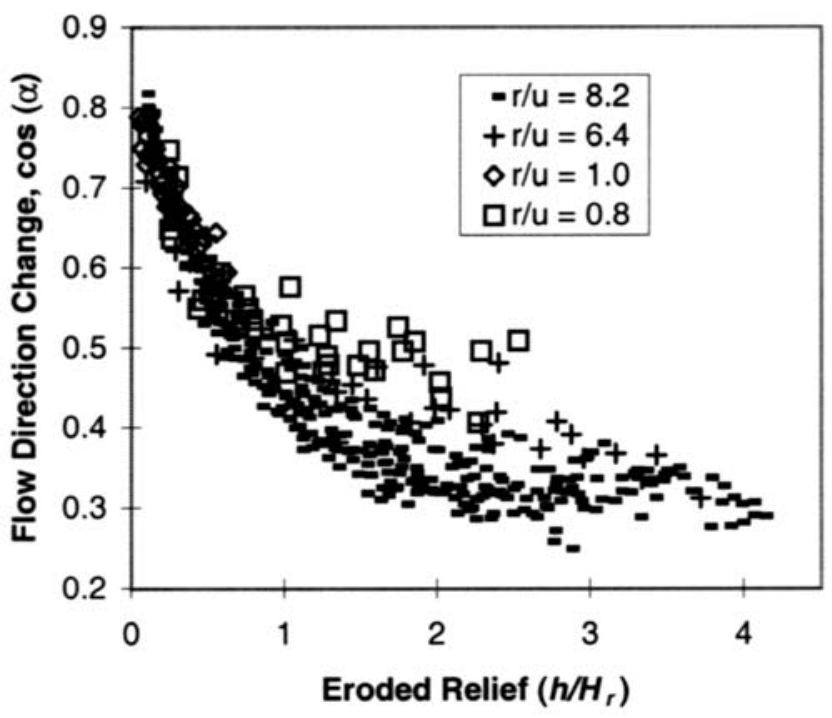

Figure 6. Average flow direction change plotted against eroded distance for 4 separate runs. The curves shift systematically with the forcing parameter $r / u$. Average angular change approaches values $>60$ for eroded distance on the order of $1 H_{r}$. Angular changes greater than 80 are improbable in our experimental basin, because flow is forced to exit the basin at a single outlet.

values between -1 (flow in opposite direction) and 1 (flow in the same direction). Summing the individual dot products, and dividing by the number of cells in the grid yields an average flow direction change. If a surface is eroding at a spatially uniform rate, we expect the relation to be a flat line with a flow direction change value of 1 , i.e., no change in flow directions with time. If the landscape experiences variable spatial erosion, directional changes plot as a curve. We plot average flow direction change for all possible time separations after complete dissection (Figure 6). Note we again convert time into fractions of $H_{r}$. The data show that the change in flow direction asymptotically approaches unity as eroded relief approaches nil, and flattens to a constant average change at longer times. At higher $r / u$ conditions, experimental landscapes develop smaller sub-basins (higher drainage density), hence a wider distribution of flow directions are possible. This results in a larger possible average flow direction change at longer times (see $r / u=8.2$, Figure 6). Average flow direction change varies between runs, suggesting dependence on forcing conditions and process activity (such as frequency and size of hillslope failures).

\section{DISCUSSION}

Stochastic erosional variability in natural landscapes could result either from stochastic forcing or intrinsic, self- 
organized variation. These are hard to separate in natural settings because atmospheric and tectonic forcing are highly variable. The experiments we report here illustrate intrinsic ("autocyclic") erosional variability at steady forcing. In an average sense, these experimental landscapes are 'adjusted' to forcing from climate and uplift, as reflected by a characteristic relief and slope for each set of uplift and rainfall conditions that we impose. We note, however, from timelapse video and animation of time series elevation data that ridges and valleys are mobile features. Such mobility requires erosional variability. Our experimental landscapes are clearly not eroding at spatially uniform rates.

What is the source of such variability? We have tried to minimize external variability by maintaining constant rainfall and uplift rates, and using a homogeneous substrate. As with any physical experiment, perfect uniformity is not possible. We observed short-term fluctuations in rainfall, on the order of 10-100 s duration, due to pressure variations in the laboratory water supply. Minor stick-slip sliding of the outlet also occurred ( $<1 \mathrm{~mm} / \mathrm{slip})$. We mixed the substrate thoroughly in a cement mixer, but small-scale heterogeneity in clay concentration in the substrate is possible. We do not think that minor fluctuations in any of these quantities can explain the temporal changes we observe in our experiment. For instance, Run 1 dried out overnight. The coefficients of variation for slope and relief are no larger than those for other runs that were conducted continuously, suggesting that dry-out ( 3 dry-out events over $1.5 H_{r}$, in this case) does not significantly alter long-term behavior and form.

The gradual change in flow direction over time suggests that lateral migration of topography occurs over time scales much longer than perturbations from rainfall and uplift. Time series animation of elevation shows that small ridge spurs (and even some longer ridge segments) are mobile over time scales of the order $0.1 H_{r} / u$. Migrating knickpoints are a common feature in all of the runs we have conducted. Our landscapes always store some sediment in valleys. The presence of temporary sediment storage implies that our experimental trunk streams are at or near carrying capacity, and cannot both incise and transport sediment on the slopes they develop. Knickpoints are the assistance mechanism to locally steepen channel slopes, and allow streams to both transport and incise. Knickpoints also interact with hillslope failures, especially in low $r / u$ conditions. Interactions work both ways, i.e., a migrating knickpoint can destabilize a hillslope, and a hillslope failure can bury a channel. For higher $r / u$, hillslope failures decrease in size and frequency, and knickpoints propagate as a wave away from the stream and up to the ridge crest, frequently generating some wobble in ridge crest location as waves reach the crest from opposite sides of the ridge slightly out of phase.
Our experiments aim at the behavior of eroding drainage basins at dynamic steady state. We already know that erosion in natural landscapes can be highly localized spatially and temporally. This is also true in our experiments. But with the added perspective of seeing the model landscape evolve through several relief distances $\left(H_{r}\right)$, we find that this short-term variability is not just minor noise on an essentially static topographic pattern. Rather, short-term variability cascades up in scale, through a set of feedbacks we have not fully identified, to induce variability in the basic ridge and valley structure of the landscape itself. The general landform characters of local and regional slope develop and fluctuate within modest limits. Within this general framework, the system behaves somewhat loosely. Ridges and valleys can migrate, extend, shorten, or be annihilated. Spatially uniform erosion displays itself only over longer time periods, on the order of the time required to erode through a relief of topography.

These results for a small steadily forced erosional drainage basin raise the possibility that natural eroding drainage basins may show strong intrinsic stochastic dynamics. Current numerical models of landscape evolution do not exhibit the same level of variability. We think that numerical models are missing some key feedback elements. Possible sources of destabilizing feedback could include sediment concentration in streams and stream incision [Sklar and Dietrich, 1998]; local erosion and deposition of sediment for streams at transport capacity; and the destabilizing influence of knickpoint propagation on adjacent hillslopes. For natural landscapes, vegetation might play a role by increasing resistance to erosion, hence steepening hillslopes. Episodic changes in vegetation, perhaps due to drought or fire, might force fluctuations in erosional resistance and increase the scale of 'erosive events' over longer times, particularly for uplifting landscapes.

\section{CONCLUSIONS}

Spatial erosion rates for our experiments are strongly dependent on the time scale of observation. Erosion rate variability increases at shorter observation times, and can be characterized by a power law relation with an exponent $2 / 3$. The exponent in the relation does not appear to be sensitive to forcing conditions. Steady state erosion rate variations on the order of $\sim 50 \%$ of the average erosion rate are still common after eroding through $\sim 0.1 H_{r}$. Temporal flow direction changes indicate a significant amount of lateral migration in experimental landscapes. Changes in flow direction exhibit greater variability at higher $r / u$ forcing conditions. Both of these measures indicate that spatial variability in erosion persists long after a balance between uplift 
and erosion has been established. We attribute variability to both small scale erosive events, such as hillslope failures and knickpoint migration, and larger scale landscape instability, such as ridge growth, migration, and annihilation.

The possibility of continuous, internally generated landscape instability raises interesting new questions about the idea of optimality in drainage networks [Rigon et al., 1993; Rinaldo et al., 1992]. If a network is constantly reconfiguring itself, can it be said to be 'optimal'? If not, does it vary about a state that is near optimal? More generally, how close are the mean properties of an ever-changing (but statistically stable) landscape to those predicted by any of the present numerical landscape models?

If natural drainage basins are capable of feedback such as we observe in our physical experiment, then prediction of erosion in landscapes may be comparable in difficulty to predicting more classical chaotic systems such as earthquakes or weather. However, if erosional variability is spatially organized in some way, (for instance, near knickpoints or migrating drainage divides), then as a first step we should be able to identify the most active regions in the basin based on knickpoint location, breaks in slope in hillslope profiles, or perhaps asymmetric ridges.

Acknowledgments. The authors express gratitude to Chris Ellis and the staff at St. Anthony Falls Laboratory for technical assistance, to G. Parker and E. Foufoula-Georgiou for stimulating discussions concerning landscape evolution, and to Y. Martin and T. Hoey for constructive reviews that improved the quality of this paper. This work has been partially supported by GSA grant \#6048-97, and by a summer research grant from the Dept. of Geology and Geophysics, University of Minnesota.

\section{REFERENCES}

Armstrong, P. A., T. A. Ehlers, P. J. J. Kamp, K. A. Farley, and D. S. Chapman, Tracking changes in exhumation rates using lowtemperature thermochronometry: an example from the Wasatch mountains, Utah (USA), in $9^{\text {th }}$ International conference on fission track dating and thermochronology, edited by W.P. Noble, P.B. O'Sullivan, and R. W. Brown, Geol. Soc. Austral. Abstr., 58, 355-356, Lorne, 2000.

Bierman, P. R., Use of in situ-produced cosmogenic isotopes to determine rates of geomorphic processes, Snowbird, Utah: AGU, Chapman Conf. Tectonics and Topography, 34, 1992.

Beaumont, C., P. Fullsack, P., and J. Hamilton, Erosional control of active compressional orogens, in Thrust Tectonics, ed. McClay K. R., Chapman and Hall, 1-18, 1992.

Brandon, M. T., M. K. Roden-Tice, and G. I. Garver, Late Cenozoic exhumation of the Cascadia accretionary wedge in the Olympic mountains, northwest Washington State, Geol. Soc. Am. Bull., 110, 985-1009, 1998.
Brown, E. T., R. F. Stallard, M. C. Larsen, G. M. Raisbeck, and F. Yiou, Denudation rates determined from the accumulation of in situ-produced 10Be in the Luquillo Experimental Forest, Puerto Rico. Earth and Planetary Science Letters, 129, 193-202, 1995.

Czirok, A., E. Somfai,, and T. Vicsek, Experimental evidence for self-affine roughening in a micromodel of geomorphological evolution, Physical Review Letters, 71, 2154-2157, 1993.

Davy, P., D. Lague, J. Kermarrec, D. Sokoutis, L. Bodet, and R. Compagnon, Analogue modelling of relief dynamics, Physics and Chemistry of the Earth (A), 25 (6-7), 549-553, 2000.

Granger, D. E., J. W. Kirchner, and R. Finkel, Spatially averaged long-term erosion rates measured from in situ-produced cosmogenic nuclides in alluvial sediment, J. Geol., 104, 249-257, 1996.

Hancock, G., Experimental testing of the Siberia landscape evolution model. Ph.D. thesis, Univ. of Newcastle, New South Wales, Australia, 1997.

Hasbargen, L. E., and C. Paola, Landscape instability in an experimental drainage basin, Geology, 28, 1067-1070, 2000.

Heimsath, A. M., W. E. Dietrich, K. Nishiizumi, and R. C. Finkel, Cosmogenic nuclides, topography, and the spatial variation of soil depth, Geomorphology, v. 27, p. 151-172, 1999.

Hovius, N., C. P. Stark, and P. A. Allen, Sediment flux from a mountain belt derived by landslide mapping, Geology, 25, 231234, 1997.

Hovius, N., C. P. Stark, H. Chu, and J. Lin, Supply and removal of sediment in a landslide-dominated mountain belt; Central Range, Taiwan, J. Geol., 1081, 73-89, 2000.

Howard, A. D., A detachment-limited model of drainage basin evolution, Water Resour. Res., 30, 2261-2285, 1994.

Lal, D., Cosmic ray labeling of erosion surfaces: in situ nuclide production rates and erosion models, Earth Planet. Sci. Lett., 104, 424-439, 1991.

Lague, D., Crave, A., and Davy, P., Laboratory experiments simulating the geomorphic response to tectonic uplift: Journal of Geophysical Research, (in press), 2002.

Martin, Y., K. Rood, , J. W. Schwab, and M. Church, Sediment transfer by shallow landsliding in the Queen Charlotte Islands, British Columbia, Can. Journ. Earth Sci., v. 39, no. 2, 189-205, 2002.

Miller, J., D. Germanoski, K. Waltman, R. Tausch, and J. Chambers, Influence of late Holocene hillslope processes and landforms on modern channel dynamics in upland watersheds of central Nevada, Geomorphology, 38, 373-39, 2001.

Moglen, G. E., and R. L. Bras, The importance of spatially heterogeneous erosivity and the cumulative area distribution within a basin evolution model, Geomorphology, 12, p. 173-185, 1995.

Parker, R. S., Experimental study of basin evolution and its hydrologic implications. Ph.D. thesis, Colorado State Univ., Fort Collins, 1977.

Phillips, L. F., and S. A. Schumm, Effect of regional slope on drainage networks, Geology, 15, 813-816, 1987.

Reneau, S., and W. Dietrich, Erosion rates in the southern Oregon Coast Range: Evidence for an equilibrium between hillslope erosion and sediment yield, Earth Surf. Processes Landforms, 16, 307-322, 1991.

Riebe, Clifford S., J. W. Kirchner, D. E. Granger, Robert C. Finkel, Erosional equilibrium and disequilibrium in the Sierra Nevada, 


\section{LOCAL EROSION RATE IN ERODING LANDSCAPES}

inferred from cosmogenic ${ }^{26} \mathrm{Al}$ and ${ }^{10} \mathrm{Be}$ in alluvial sediment Geology, 28, 803-806, 2000.

Rigon, R., A. Rinaldo, I. Rodriguez-Iturbe, R. Bras, and E. IjjaszVasquez, Optimal channel networks: a framework for the study of river basin morphology, Water Resour. Res., 29, 1635-1646, 1993.

Rinaldo, A., I. Rodriguez-Iturbe, R. Rigon, R. Bras, E. IjjaszVasquez, A. Marani, Minimum energy and fractal structures of drainage networks, Water Resour. Res, 28, 2183-2195, 1992.

Shreve, R. L., The probabilistic-topologic approach to drainagebasin geomorphology, Geology, 3, 527-529, 1975.

Shreve, R. L., Infinite topologically random channel networks, $J$. Geol, 75, 178-186, 1967.

Sklar, L., and W. Dietrich, River longitudinal profiles and bedrock incision models: Stream power and the influence of sediment supply, in Rivers over rock: Fluvial Processes in Bedrock Channels, Geophys. Monogr. Ser., vol. 107, edited by K. J. Tinkler and E. E. Wohl, pp. 237-260, AGU, Washington D. C., 1998.
Whipple, K. X., and G. E. Tucker, Dynamics of the stream-power river incision model: Implications for height limits of mountain ranges, landscape response timescales, and research needs, $J$. Geophys. Res., 104, 17,661-17,674, 1999.

Willgoose, G., R. Bras, and I. Rodriguez-Iturbe, A coupled channel network growth and hillslope evolution model, 1. Theory, Water Resour. Res, 27, 1671-1684, 1991.

Wolf, P. R., Elements of Photogrammetry, Second Edition, McGraw-Hill Book Company, 1983.

Leslie E. Hasbargen, Department of Geology and Geophysics, 310 Pillsbury Drive SE, University of Minnesota, Minneapolis, MN 55455. (hasba002@tc.umn.edu)

Chris Paola, Department of Geology and Geophysics, 310 Pillsbury Drive SE, University of Minnesota, Minneapolis, MN 55455. (cpaola@umn.edu) 